\title{
Elastic properties and apparent density of human edentulous maxilla and mandible
}

\author{
Wook-Jin Seong ${ }^{1}$, Uk-Kyu Kim² ${ }^{2}$, James Q. Swift ${ }^{3}$, Young-Cheul Heo ${ }^{1}$, James S. Hodges ${ }^{4}$, \\ and Ching-Chang $\mathrm{Ko}^{5}$ \\ ${ }^{1}$ Department of Restorative Science, School of Dentistry, University of Minnesota, 515 Delaware \\ Street SE, Minneapolis, MN 55455 USA \\ ${ }^{2}$ Department of Oral and Maxillofacial Surgery, College of Dentistry, Pusan National University, 1-10 \\ Ami-dong Seo-gu, Pusan 602-739 South Korea \\ ${ }^{3}$ Department of Developmental and Surgical Sciences, School of Dentistry, University of Minnesota, \\ 515 Delaware Street SE, Minneapolis, MN 55455 USA
}

${ }^{4}$ Division of Biostatistics, School of Public Health, University of Minnesota, 2221 University Ave SE, Suite 200, Minneapolis, MN 55455 USA

${ }^{5}$ Department of Orthodontics, University of North Carolina at Chapel Hill, Manning Dr. \& Columbia St. CB\#7450, Chapel Hill, NC 27599-7450 USA

\begin{abstract}
The aim of this study aim was to determine whether elastic properties and apparent density of bone differ in different anatomical regions of the maxilla and mandible. Additional analyses assessed how elastic properties and apparent density were related. Four pairs of edentulous maxilla and mandibles were retrieved from fresh human cadavers. Bone samples from four anatomical regions (maxillary anterior, maxillary posterior, mandibular anterior, mandibular posterior) were obtained. Elastic modulus (EM) and hardness $(\mathrm{H})$ were measured using the nano-indentation technique. Bone samples containing cortical and trabecular bone were used to measure composite apparent density (cAD) using Archimedes' principle. Statistical analyses used repeated measures ANOVA and Pearson correlations. Bone physical properties differed between regions of the maxilla and mandible. Generally, mandible had higher physical property measurements than maxilla. EM and $\mathrm{H}$ were higher in posterior than in anterior regions; the reverse was true for $\mathrm{CAD}$. Posterior maxillary cAD was significantly lower than that in the three other regions.
\end{abstract}

\section{Keywords}

elastic modulus; hardness; apparent density; human maxilla; mandible

Dental implants have a high success rate overall, but implants placed in the posterior maxilla often fail ${ }^{2,9}$. This difference in clinical performance may be linked to the bone quality in

\footnotetext{
(C) 2009 International Association of Oral and Maxillofacial Surgeons. Published by Elsevier Ltd. All rights reserved. Corresponding Author: Wook-Jin Seong, 9-470 Moos Tower, 515 Delaware Street SE, Minneapolis, MN 55455 USA, TEL: (612) 625-5677, FAX: (612) 626-1496, E-MAIL: seong001@umn.edu.

Publisher's Disclaimer: This is a PDF file of an unedited manuscript that has been accepted for publication. As a service to our customers we are providing this early version of the manuscript. The manuscript will undergo copyediting, typesetting, and review of the resulting proof before it is published in its final citable form. Please note that during the production process errors may be discovered which could affect the content, and all legal disclaimers that apply to the journal pertain.
} 
different anatomical regions. A prospective multi-center study 22 reported $23 \%$ of maxillary posterior regions had type 4 (poor) bone quality compared with 1-3\% in the mandible. Lekholm and Zarb ${ }^{12}$ proposed a classification of bone quality (types 1-4) based on the amount of cortical bone and the sparseness of trabecular bone. Numerous studies have attempted to correlate this bone quality classification with implant success rate. This classification is accepted clinically because it is convenient, but it is abstract and subjective. Other quantitative measurements such as bone density and/or stiffness might be more appropriate, providing objectivity for diagnosis, treatment and research.

The material properties of bone and their variations in different types and regions of bone are important for understanding how bone responds and adapts to mechanical environment changes and are essential for accurate numerical modeling. The elastic properties (elastic modulus and hardness) of the bone contacting the implant and the amount of bone (apparent density) surrounding the implant might be important factors determining implant stability and success. Numerous papers have described the physical and mechanical properties of bone, especially the long bone in the field of orthopedics. There are limited studies $8,13,16,21$ on the quantitative physical properties of human mandibles in relation to anatomical regions. It is difficult to find studies measuring the physical properties of the maxilla, mainly because it is difficult to obtain maxillary test samples with the specific dimensions required for techniques such as the three point bending and compression testing, since available bone is weak and limited in quantity.

The nano-indentation technique applies a micron-level sized indenter tip to the bone surface to measure the elastic properties of bone, thus eliminating the need to prepare bone samples of specific sizes. Since individual trabeculae are typically less than $500 \mu \mathrm{m}$ thick, it is advantageous to use a technique that allows examination of the elastic properties at the microstructural level. Rho et al. ${ }^{18}$ used nano-indentation to measure the elastic modulus (EM) and hardness $(\mathrm{H})$ of individual trabeculae, osteons, and interstitial lamellae in human vertebrae and tibia.

Apparent density can be defined as 'mass of bone tissue divided by the bulk volume of the test specimen, including mineralized bone and marrow space ${ }^{14}$. Trabecular bone typically varies in porosity (marrow space), and the apparent density concept has been used extensively to define trabecular bone characteristics. A fully mineralized solid matrix of bone, such as cortical bone, is regarded as quite uniform and its density is typically measured.

In the current study, cross-sectioned whole bone samples ( $3 \mathrm{~mm}$ thick, $10 \mathrm{~mm}$ long from the crest of alveolar ridge) containing cortical bone shell and inner trabecular bone were used to measure composite (cortical plus trabecular) apparent density (cAD) using Archimedes' principle. It was decided not to measure cortical bone density and trabecular bone apparent density separately because there was not enough cortical or trabecular bone in the maxilla and certain areas of the mandible to make specific-sized samples. There is no known formula to combine cortical bone density and trabecular bone apparent density to obtain a region-specific apparent density.

The objectives of the current study were to determine whether and how elastic properties (EM and $\mathrm{H}$ ) and composite apparent density (cAD) differ in 4 anatomical regions of the jawbone (maxillary anterior, maxillary posterior, mandibular anterior, mandibular posterior), and to see whether these physical properties are related. 


\section{Material and methods}

\section{Sample preparation}

Four sets of human edentulous maxilla and mandibles were retrieved from fresh cadavers (dead for $<72 \mathrm{~h}$ ). All four were males without any known bone disorders. Their mean age was 83.25 $(72,91,85,85$ years). Different anatomical regions (maxillary anterior, maxillary posterior [left and right], mandibular anterior, mandibular posterior [left and right]) were marked with indelible marker (Fig. 1). Anterior and posterior, $20 \mathrm{~mm}$ long, bone blocks represented the central incisor area and molar area, respectively. The midline was used to locate the center of the anterior mandibular and maxillary blocks. The mesial border of the posterior mandibular block was located $3.5 \mathrm{~mm}$ distal to the mental foramen midline. The distal border of the posterior maxillary block was located $8.5 \mathrm{~mm}$ mesial to the distal surface of the maxillary tuberosity. Each $20 \mathrm{~mm}$ long bone block was divided into three sections; one $8 \mathrm{~mm}$ middle section and two $6 \mathrm{~mm}$ side sections. The $8 \mathrm{~mm}$ middle sections were saved for future histomorphometric study. Each $6 \mathrm{~mm}$ side section was further divided into two $3 \mathrm{~mm}$ slices using a low-speed diamond blade saw (Isomet, Buehler, Lake Bluff, IL, USA), of which one was assigned to the nano-indentation and one to apparent density measurement.

\section{Nano-indentation}

For nano-indentation, the bone marrow of each unfixed $3 \mathrm{~mm}$ thick bone sample was removed with a water jet and bone was dehydrated with a graded series of alcohol. A total of 48 bone samples ( 2 samples/block $\times 6$ blocks/cadaver $\times 4$ cadavers) were embedded in photopolymerizing resin (Technovit $7200 \mathrm{VLC}$, Kulzer, Germany) under vacuum to provide support for the bone network. After resin embedding, a micro-grinding system was used to expose the bone surface ${ }^{17}$. Nano-indentation was performed to measure EM and H using the Nano Indenter ${ }^{\circledR}$ XP (MTS Systems Corp., Oak Ridge, TN, USA) instrument and software. This system makes small indentations at precise intervals on a specimen surface while continuously monitoring the loads and displacement. Nine 50 -micron interval indentations (in a $3 \times 3$ square) were made at four locations (two cortical and two trabecular bone locations) on each bone sample (Fig. 2). Each nano-indentation test was performed to a maximum load of $100 \mathrm{mN}$ at a constant loading rate of $1 \mathrm{mN} / \mathrm{s}$, the indenter was held for a period of $10 \mathrm{~s}$ at this peak load and then unloaded at the rate of $1 \mathrm{mN} / \mathrm{s}$. EM and $\mathrm{H}$ were calculated using the Oliver-Pharr method ${ }^{15}$ from the force-displacement graphs obtained for each indentation.

\section{Composite apparent density}

The other $3 \mathrm{~mm}$ thick, $10 \mathrm{~mm}$ long cross-sectioned bone sample containing cortical and trabecular bone was obtained from the crest of the alveolar ridge. Apparent density was calculated as mass divided by volume. Since both cortical and trabecular bone were included in the sample, the term cAD was used. A new technique, making an impression of the bone sample, was used to measure the volume of bone specimens. The conventional pycnometer technique of measuring water volume displaced by the specimen did not work well because the bone samples were large, so the orifice of the custom made pycnometer also had to be large, which induced larger errors in measuring displaced water volume. Instead, a thin layer of wax was applied to the surface of the bone sample to prevent the impression material from penetrating the sample. An impression of the wax-covered bone sample was made using polyvinylsiloxane impression material (Examix NDS regular, GC America Inc, IL, USA) and a plastic container. After the bone sample was removed from the impression, distilled water was poured into the space until the water surface was level with the surface of the impression material. The weight of water filling the space was measured three times by repeating the above procedure (Fig. 3). The average of the three weight measurements was used for the volume of water and also as the volume of the bone sample, since the specific gravity of water is 1 . The bone sample was treated under steam and then with xylene for $2 \mathrm{~min}$ to remove the wax. The 
specimen was immersed in ether for $12 \mathrm{~h}$ and then $60 \%, 80 \%, 100 \%$ alcohol, for $1 \mathrm{~h}$ each, to dehydrate it. The sample was vacuum dried for $6 \mathrm{~h}$ and its dry weight was measured using Mettler AE240 analytical balance (Mettler Instrument Corp., Hightstown, NJ, USA) (Fig. 4).

\section{Statistical analyses}

Statistical analyses mainly used mixed linear models, a generalization of repeated measures ANOVA. In these analyses the dependent variables were elastic properties (EM and $\mathrm{H}$ ) or cAD, each measured repeatedly on four 'subjects' (the cadavers). Based on a Box-Cox test, $\log _{10} \mathrm{cAD}$ was analyzed instead of $\mathrm{AD}$. The fixed effects in this analysis were jawbone (maxilla vs. mandible), region (anterior vs. posterior), and bone type (cortical vs. trabecular). The small number of 'subjects' does not necessarily imply low power because all of the fixed effects were within-subject comparisons. The adjusted averages of EM, $\mathrm{H}$ and cAD measurement were compared between 4 anatomical regions (maxillary anterior, maxillary posterior, mandibular anterior, mandibular posterior) using a Bonferroni corrected p-value threshold of $0.0083(=0.05 / 6)$. All of the analyses used the MIXED procedure in the SAS statistical package (v. 8.2; SAS Institute, Inc., Cary, NC, USA) with the restricted likelihood method. Pearson's correlation coefficient (r) was also computed for each pair of physical property measurements.

\section{Results}

Tables 1 and 2 give ANOVA-style fixed effects tests and adjusted averages for dependent variables EM, $\mathrm{H}$ and $\mathrm{CAD}$. All 3 variables had significantly higher measurements in mandible compared with maxilla. Mandibular cAD was $76 \%$ higher than maxillary cAD (1.18 vs. 0.67 $\left.\mathrm{g} / \mathrm{cm}^{3}\right)$. EM and $\mathrm{H}$ in the posterior region were significantly higher than in the anterior region while $\mathrm{cAD}$ showed the opposite, although the differences were not significant $(\mathrm{p}=0.064)$. EM was significantly higher in cortical compared with trabecular bone, while the $\mathrm{H}$ of cortical and trabecular bone were similar.

Tables 3 and 4 show adjusted averages and p-values, respectively, comparing physical properties among 4 anatomical regions (maxillary anterior, maxillary posterior, mandibular anterior, mandibular posterior). P-values were computed to a Bonferroni-adjusted threshold of $0.0083(=0.05 / 6)$. Mandibular posterior was significantly superior to maxillary posterior and maxillary anterior for all 3 physical properties. In the mandible, posterior bone cAD and anterior bone $\mathrm{CAD}$ were roughly the same but anterior $\mathrm{cAD}$ was significantly higher than posterior cAD in maxilla.

Table 5 shows Pearson's correlations (r) between these 3 physical property measurements. All 3 pairs showed significant correlations.

\section{Discussion}

Earlier studies reported different success rates in different regions of the jawbone: $97 \%, 99 \%$, $89 \%$, and $71 \%$ in 673 implants $^{9} ; 100 \%, 94 \%, 92 \%$, and $74 \%$ in 137 implants $^{7} ; 94 \%, 95 \%$, $88 \%$, and $87 \%$ in 2359 implants $^{3}$, in anterior mandible, posterior mandible, anterior maxilla and posterior maxilla, respectively.

In the current study, cAD was lower in the posterior maxilla than in any other region. For EM and $\mathrm{H}$, posterior bone was superior to anterior bone. These findings suggest that the amount of cortical bone and trabecular bone per unit volume available for implant is more important for implant success, than stiffness of the cortical bone or trabeculae in contact with an implant. 
EM represents the ratio of applied stress to change in shape of an elastic body. The higher the bone's EM, the more stress is needed to induce a unit deformation. EM measured by nanoindentation can be slightly different from EM measured by conventional three-point bending or compression testing. The nano-indentation technique allows measurement of the intrinsic material property of bone, which is independent of the specimen size, while the elastic properties measured by 3-point bending or compression testing are affected by the size and shape of the sample, which might reflect a mixture of structural and material properties.

Nano-indentation also has several limitations. Bushby et al. ${ }^{4}$ performed nano-indentation on 11 rectangular $(5 \times 2 \times 25 \mathrm{~mm})$ cortical specimens from horse metacarpal bone to see the effects of dehydration and polymethyl methacrylate embedding of the bone sample. They reported that the modulus increased from 11.2 to 12.5 to $19.5 \mathrm{GPa}$, for wet, dehydrated in ethanol, and embedded conditions, respectively. This might explain why nano-indentation EM is, in general, higher than EM measured with mechanical tests. When the bone surface was rough due to poor polishing or when the specimen surface was slanted against the indenter, errors might have occurred, but those are not common or inherent problems. Bushby et al. ${ }^{4}$ found that indenting with higher loads increased the volume of material contributing to the EM measurement and reduced surface effects on the measured modulus value. The present experiments used $100 \mathrm{mN}$ compared with $20 \mathrm{mN}$ used in the Rho et al. ${ }^{17}$ study.

The current study found that EM differed significantly between maxilla (14.9 GPa) and mandible (18.3 GPa). Also, posterior jawbone (17.5 GPa) had significantly higher EM than anterior jawbone (15.7 GPa), perhaps because of adaptation to higher chewing force in the posterior part of the jawbone. The EM of cortical bone (17.7 GPa) and trabecular bone (15.4 $\mathrm{GPa}$ ) (averaging together maxillas and mandibles) also differed significantly. This result agrees with previous findings ${ }^{6,11}$ that cortical bone EM is higher than trabecular bone EM. Wolff's assumption that compact bone is simply more dense cancellous bone, so cortical and trabecular bones should have approximately the same elastic properties might not be accurate, based on the current and above mentioned studies.

Few previous studies have measured apparent density of jawbones. O'Mahony et al. ${ }^{16}$ reported a mean hydrated apparent density of $0.55 \mathrm{~g} / \mathrm{cm}^{3}$ from an edentulous mandibular trabecular bone from a 74-year-old female. Misch et al. ${ }^{13}$ presented a mean apparent density with bone marrow in situ of $1.18 \mathrm{~g} / \mathrm{cm}^{3}$ from 9 human mandibular trabecular bones. Schwartz-Dabney and Dechow ${ }^{21}$ reported a density of $1.85-2.0 \mathrm{~g} / \mathrm{cm}^{3}$ from 10 dentate human mandibular cortical bones. The present study's composite (cortical plus trabecular) apparent density, averaging $1.18 \mathrm{~g} / \mathrm{cm}^{3}$ in the mandible and $0.67 \mathrm{~g} / \mathrm{cm}^{3}$ in the maxilla, is well situated among these previous estimates.

EM and $\mathrm{H}$ were calculated from the identical indentation on the same bone sample, so their high association was expected. The $\mathrm{CAD}$ indicates the amount (quantity) of cortical and trabecular bone per unit volume, while lamella level EM measured by nano-indentation represents the intrinsic mechanical properties of the bone tissue, so they can be independent each other and their moderate correlation can be explained.

The relation between EM and apparent density has been extensively studied. Trabecular bone EM from compression tests was found to be proportional to the cube of the apparent density and strength proportional to the square of the apparent density. ${ }^{5}$ Both Young's modulus and strength were found to be proportional to the square of apparent density. ${ }^{19}$ Mandibular trabecular bone showed a linear relationship between density and EM and a cubic relationship between density and strength ${ }^{13}$. In the present study, EM and cAD showed reasonable agreement with a linear relationship $(\mathrm{r}=0.52)$, and similar agreement with a cubic relationship, between $\mathrm{EM}$ and $\mathrm{cAD}^{3}(\mathrm{r}=0.51)$. Since the present study used the nano-indentation method to 
measure $\mathrm{EM}$, not the compression test, and $\mathrm{CAD}$ was measured from specimens containing both cortical and trabecular bone, a different relationship might be expected.

Aging effects on elastic properties might be difficult to predict. Hoffler et al. ${ }^{10}$ measured EM and $\mathrm{H}$ using nano-indentation on proximal femurs from 27 cadavers and found that age, gender, height, body mass and body mass index were not correlated with lamellar-level EM or H. These authors suggested age- and gender-related decreases in mechanical integrity do not involve alterations in $\mathrm{EM}$ or $\mathrm{H}$ of the extra-cellular matrix.

Age-related bone loss has been associated with a decrease in bone density and mineral content in cortical and trabecular bone. Atkinson and Woodhead ${ }^{1}$ measured the bone density of mandibular cortical bone from 43 subjects (aged 44-84 years) and found that cortical bone became less dense and had more porosity with increasing age, while tooth loss did not induce a significant density change but rather a reduction of alveolar bone crest height. Owing to the edentulism and high average age ( 83.3 years) of the subjects in the current study, it is reasonable to expect the lower level of $\mathrm{cAD}$ measurements found.

One finding in the current study that might be related to aging, is that fatty degeneration was often found in the posterior maxillary alveolar ridge, with its cortical bone surface relatively hard. Schnitzler and Mesquita ${ }^{20}$ measured fatty degeneration on iliac crest bones in 98 subjects. They found that the extent of fatty degeneration increased with age and concluded that fatty degeneration, which may have occupied space vacated by bone loss, was an aging phenomenon. Assuming that fatty degeneration increased in the current study's 4 subjects as they aged, it is not clear why only posterior maxillary alveolar bone showed prominent fatty degeneration. Regardless of the causes, the frequent appearance of fatty degeneration in the posterior maxilla probably contributed to its having the lowest $\mathrm{CAD}$ measurement.

Wang and Puram ${ }^{24}$ defined toughness as a quantitative measure of bone quality in terms of its susceptibility to fracture. A few earlier studies ${ }^{25}$ showed that fracture toughness of cortical bone depends on bone density. Wang et al. ${ }^{23}$ studied the relationship of fracture toughness to other physical bone properties in femurs from 18 baboons. They found that fracture toughness of bone decreased as age increased and only micro-hardness changed significantly (increased) while other parameters, such as bone mineral density, EM, yield strength and porosity did not.

The clinically observed low implant success rates in the posterior maxilla might be because the posterior maxilla has the lowest $\mathrm{cAD}$ and relatively high $\mathrm{H}$, which might indicate low fracture toughness. This could lead to relatively easy fractures of bone during surgical drilling and implant insertion, and resultant low implant stability and success. The current study did not provide quantitative evidence of the extent of fatty degeneration or fracture toughness, but it suggests that aging and its effects on fatty degeneration and fracture toughness, in at least the posterior maxilla, should be further studied, and that implant surgery on the posterior maxilla in elderly patients should be planned cautiously.

\section{Acknowledgements}

This research was partially supported by NIH/NIDCR R21-DE015410 grant. The authors would like to thank Dr Michelle Oyen for her support during nano-indentation.

\section{References}

1. Atkinson P, Woodhead C. Changes in human mandibular structure with age. Archs Oral Biol 1968;13:1453-1463. 
2. Becker W, Becker BE, Alsuwyed A, Al-Mubarak S. Long-term evaluation of 282 implants in maxillary and mandibular molar positions: a prospective study. J Periodontol 1999;70:896-901. [PubMed: 10476898]

3. Buser D, Mericske-Stern R, Bernard JP, Behneke A, Behneke N, Hirt HP, Belser UC, Lang NP. Longterm evaluation of non-submerged ITI implants. Part 1: 8-year life table analysis of a prospective multicenter study with 2359 implants. Clin Oral Impl Res 1997;8:161-172.

4. Bushby A, Ferguson V, Boyde A. Nano-indentation of bone: Comparison of specimens tested in liquid and embedded in polyethylmethacrylate. J Mater Res 2004;19:249-259.

5. Carter D, Hayes W. Bone compressive strength: the influence of density and strain rate. Science 1976;194:1174-1175. [PubMed: 996549]

6. Choi K, Kuhn J, Ciarelli M, Goldstein S. The elastic moduli of human subchondral, trabecular, and cortical bone tissue and the size-dependency of cortical bone modulus. J Biomech 1990;23:1103-13. [PubMed: 2277045]

7. Da Silva JD, Schnitman PA, Wohrle PS, Wang HN. Influence of site on implant survival: 6-year results. J Dent Res 1992;71:256.

8. Dechow P, Nail G, Schwartz-Dabney C, Ashman R. Elastic properties of human supraorbital and mandibular bone. Am J Phys Antropol 1993;90:291-306.

9. Drago CJ. Rates of osseointegration of dental implants with regard to anatomical location. J Prosthod 1992;1:29-31.

10. Hoffler C, Moore K, Kozloff K, Zysset P, Goldstein S. Age, gender, and bone lamellae elastic moduli. J Orthp Res 2000;18:432-437.

11. Kuhn J, Goldstein S, Choi K, London M, Feldkamp L, Mathews L. Comparison of the trabecular and cortical tissue moduli from human iliac crests. J Orthop Res 1989;7:876-884. [PubMed: 2795328]

12. Lekholm, U.; Zarb, G. Patient selection and preparation. In: Branemark, PI.; Zarb, GA.; Albrektsson, T., editors. Tissue-integrated prostheses: osseointegration in clinical dentistry. Quintessence Publishing Co.; Chicago: 1985. p. 199-209.

13. Misch C, Zhimin Q, Bidez M. Mechanical properties of trabecular bone in the human mandible: implications for dental implant treatment planning and surgical placement. J Oral Maxillofac Surg 1999;57:700-706. [PubMed: 10368096]

14. Mow, VC.; Hayes, WC. Basic orthopedic biomechanics. Liooincott-Raven; Philadelphia: 1997. p. 86-106.

15. Oliver W, Pharr G. An improved technique for determining hardness and elastic modulus using load and displacement sensing indentation experiments. J Mater Res 1992;7:1564-1583.

16. O'Mahony A, Williams J, Katz J, Spencer P. Anisotropic elastic properties of cancellous bone from a human edentulous mandible. Clin Oral Impl Res 2000;11:415-21.

17. Rho J, Roy M II, Tsui T, Pharr G. Elastic properties of microstructural components of human bone tissue as measured by nano-indentation. J Biomed Mater Res 1999;45:48-54. [PubMed: 10397957]

18. Rho J, Tsui T, Pharr G. Elastic properties of human cortical and trabecular lamellar bone measured by nano-indentation. Biomaterials 1997;18:1325-1330. [PubMed: 9363331]

19. Rice J, Cowin S, Bowman J. On the dependence of the elasticity and strength of cancellous bone on apparent density. J Biomechanics 1988;21:155-168.

20. Schnitzler C, Mesquita J. Bone marrow composition and bone microarchitecture and turnover in blacks and whites. J Bone Miner Res 1998;13:1300-1307. [PubMed: 9718199]

21. Schwartz-Dabney C, Dechow P. Variations in cortical material properties throughout the human dentate mandible. Am J Phys Anthropol 2003;120:252-277. [PubMed: 12567378]

22. Truhlar RS, Lauciello F, Morris HF, Ochi S. The influence of bone quality on Periotest values of endosseous dental implant at stage II surgery. J Oral Maxillofac Surg 1997;55(12 supple 5):55-61. [PubMed: 9393427]

23. Wang XD, Masilamani N, Mabrey J, Alder M, Agrawal C. Changes in the fracture toughness of bone may not be reflected in its mineral density, porosity, and tensile properties. Bone 1998;23:67-72. [PubMed: 9662132]

24. Wang XD, Puram S. The toughness of cortical bone and its relationship with age. Ann Biomed Eng 2004;32:123-135. [PubMed: 14964728] 
25. Wright T, Hayes W. Fracture mechanics parameters for compact bone - effects of density and specimen thickness. J Biomech 1977;7:419-430. [PubMed: 885894] 


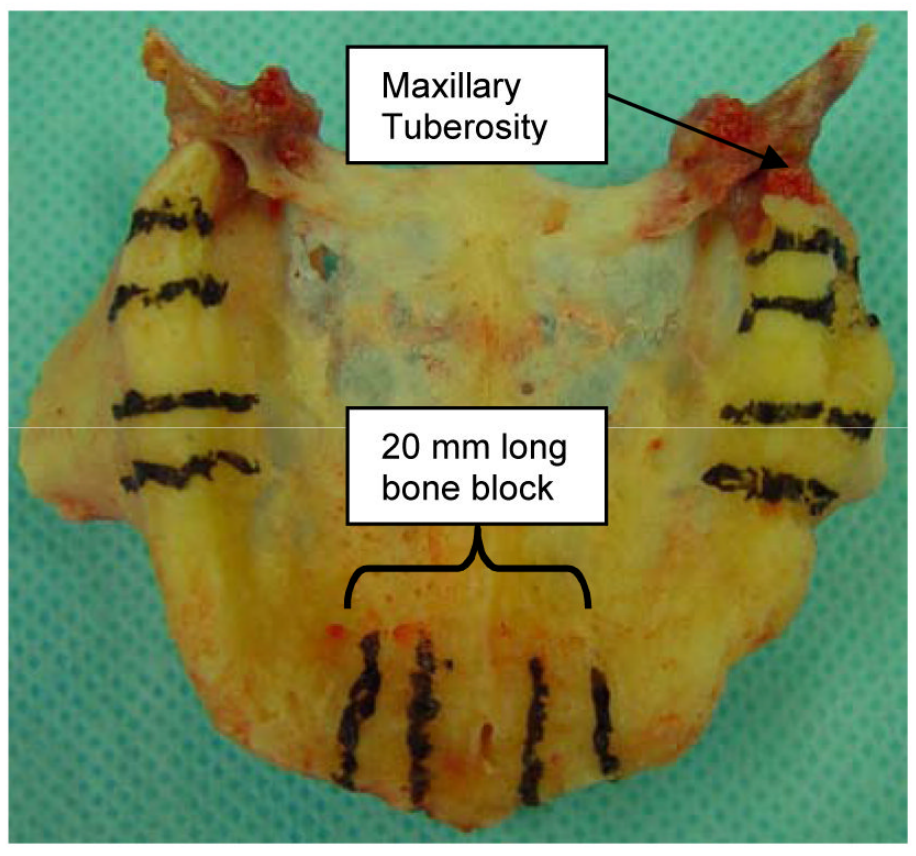

(b)

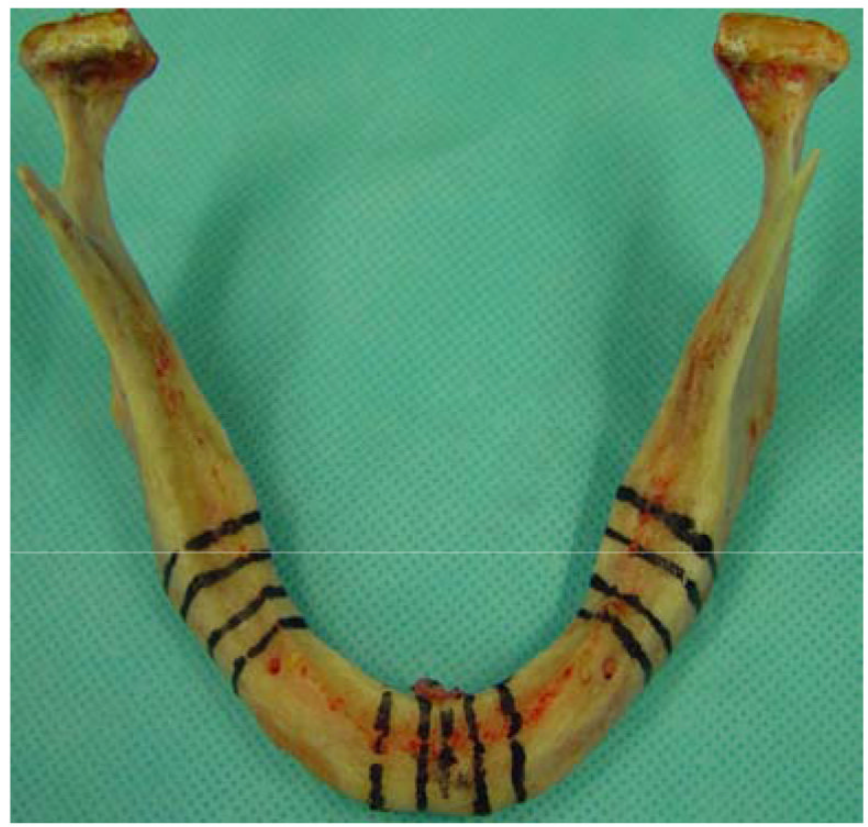

Figure 1.

Marking the anterior and posterior $10 \mathrm{~mm}$ long bone blocks in (a) maxilla and (b) mandible. 


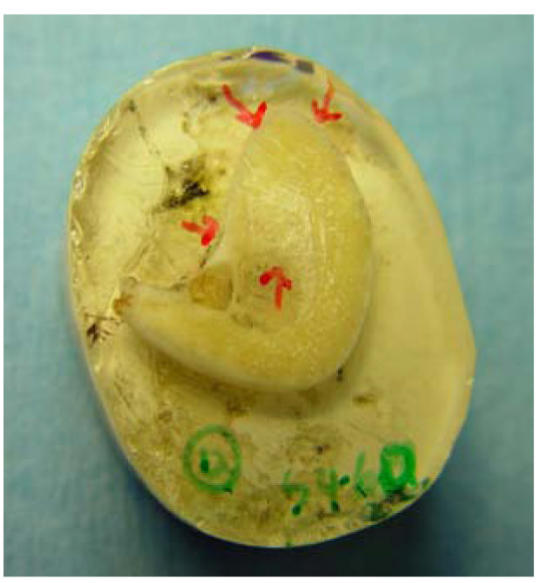

(a)

(b)

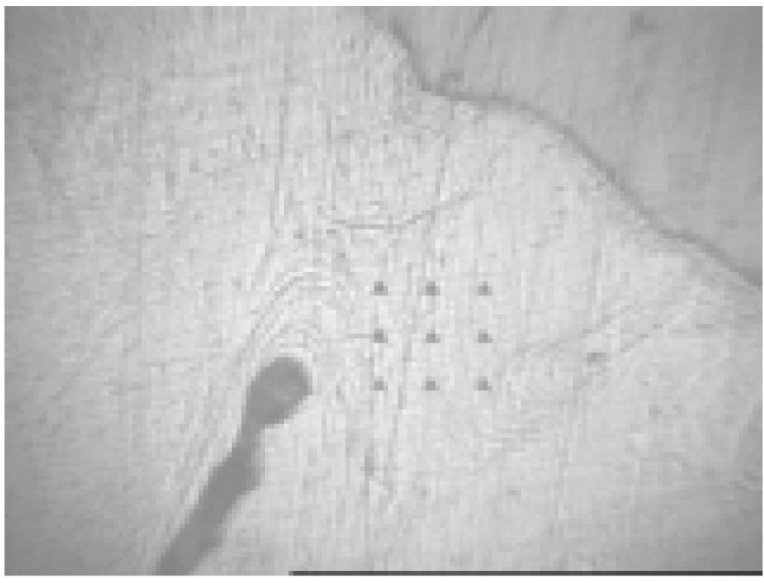

Figure 2.

Nano-indentation. (a) Two locations on cortical bone and two locations on trabecular bone were selected for nano-indentation. (b) Nine indentations ( $3 \times 3$ square) on a cortical bone location. 


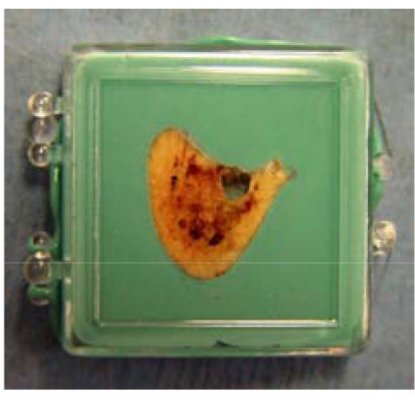

(b)
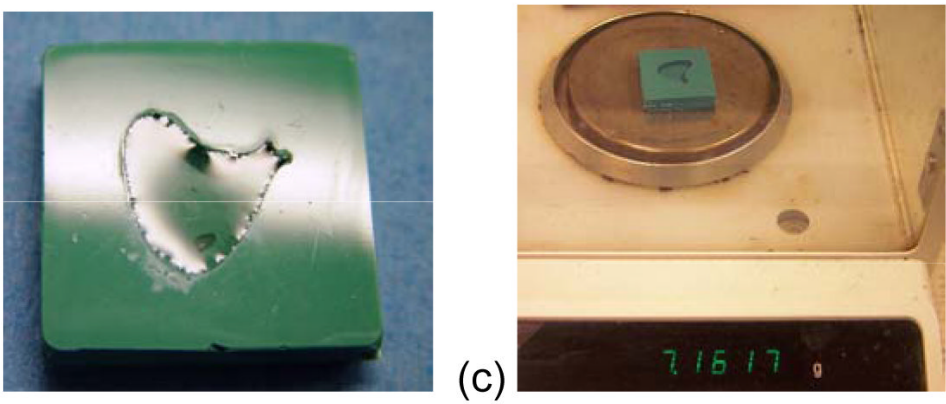

Figure 3.

Measuring the volume of the bone sample. (a) Impression of wax-covered bone specimen (waxcovered side was facing downward). (b) Distilled water filled the empty space. (c) Water weight measured using balance. 
(a)

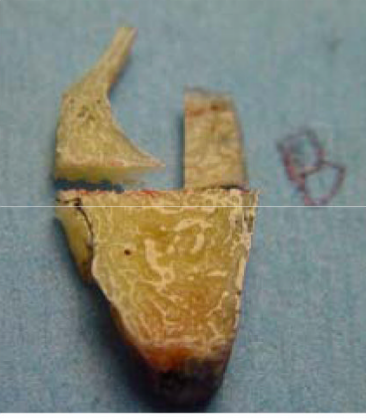

(b)

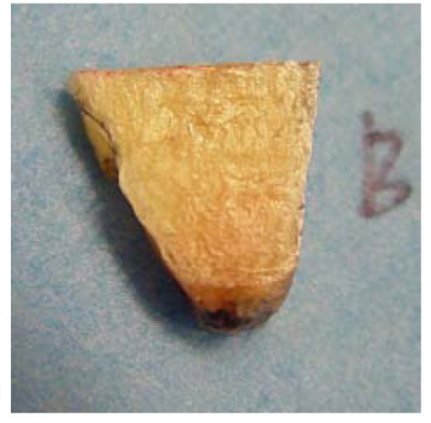

(c)

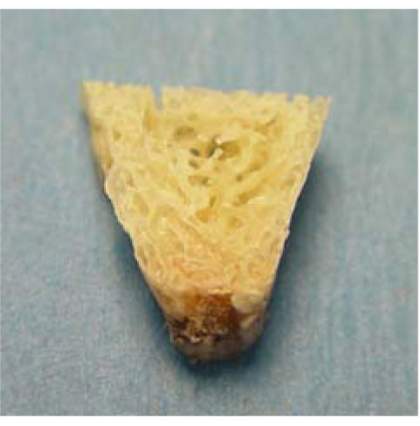

Figure 4.

Sample treatment to measure bone cAD. (a) $10 \mathrm{~mm}$ long, $3 \mathrm{~mm}$ thick cross-sectioned sample cut out. (b) Thin layer of wax applied to cover the bone surface before making impression to measure bone volume. (c) Bone sample dehydrated and vacuum dried to obtain dry bone weight. 
Tests of fixed effects

Table 1

\begin{tabular}{|c|c|c|c|}
\hline & EM & $\mathbf{H}$ & $\log (\mathbf{c A D})$ \\
\hline Effect & p-value & p-value & p-value \\
\hline Maxilla vs. Mandible & $<.0001^{*}$ & $0.0002^{*}$ & $<.0001^{*}$ \\
\hline Anterior vs. Posterior & $0.0169^{*}$ & $0.0207^{*}$ & 0.0640 \\
\hline Cortical vs. Trabecular & $<.0001^{*}$ & 0.2284 & \\
\hline Mx/Mn-by-Ant/Post & 0.1511 & 0.3606 & 0.0531 \\
\hline Mx/Mn-by-Cort/Trab & $0.0090^{*}$ & 0.6273 & \\
\hline Ant/Post-by-Cort/Trab & 0.6706 & 0.2220 & \\
\hline Mx/Mn-by-Ant/Post-by-Cort/Trab & $0.0471^{*}$ & 0.1709 & \\
\hline
\end{tabular}




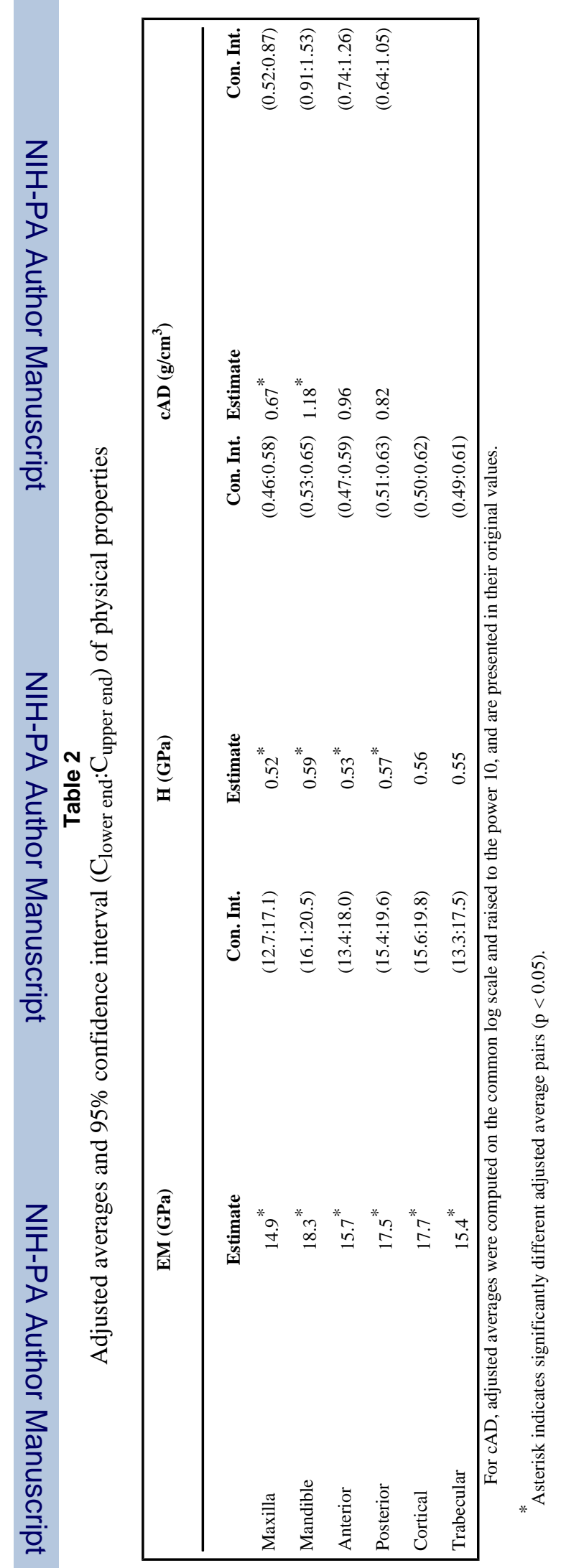

Int J Oral Maxillofac Surg. Author manuscript; available in PMC 2010 October 1. 


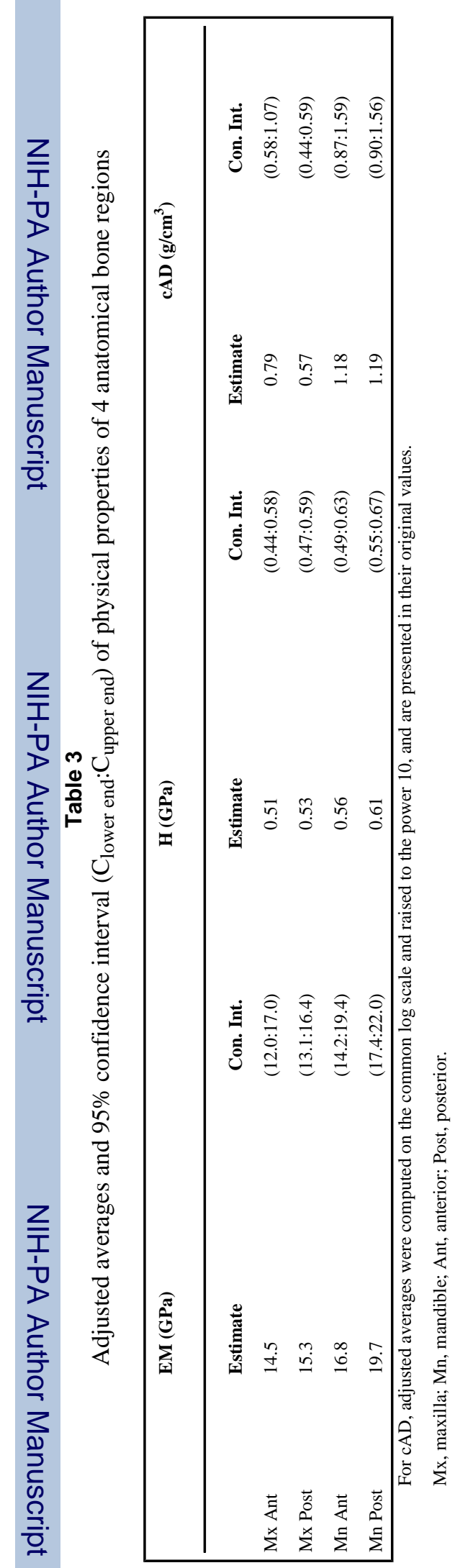

Int J Oral Maxillofac Surg. Author manuscript; available in PMC 2010 October 1. 
Table 4

Comparison of physical properties of all pairs of 4 anatomical bone regions

\begin{tabular}{|c|c|c|c|}
\hline & EM & $\mathbf{H}$ & $\log (\mathbf{c A D})$ \\
\hline Comparison & p-value & p-value & p-value \\
\hline Mn Ant minus Mn Post & 0.0126 & 0.0318 & 0.9492 \\
\hline Mn Ant minus Mx Ant & 0.0608 & 0.0491 & 0.0088 \\
\hline Mn Ant minus Mx Post & 0.1360 & 0.1889 & $<.0001^{*}$ \\
\hline Mn Post minus Mx Ant & $<.0001^{*}$ & $<.0001^{*}$ & $0.0026^{*}$ \\
\hline Mn Post minus Mx Post & $<.0001^{*}$ & $<.0001^{*}$ & $<.0001^{*}$ \\
\hline Mx Ant minus Mx Post & 0.4114 & 0.2506 & $0.0083^{*}$ \\
\hline \multicolumn{4}{|c|}{ Bonferroni corrected p-value threshold is $0.0083(=0.05 / 6)$} \\
\hline \multicolumn{4}{|c|}{ Mx, maxilla; Mn, mandible; Ant, anterior; Post, posterior. } \\
\hline
\end{tabular}


Table 5

Pearson correlations among three physical properties of the jawbone

\begin{tabular}{llccc} 
Variable & by Variable & Correlation $(\mathbf{r})$ & P-value \\
Z & EM & $\mathrm{H}$ & 0.920 & $<0.000$ \\
\hline $\mathrm{I}$ & $\mathrm{cAD}$ & 0.516 & 0.005 \\
$\mathrm{EM}$ & $\mathrm{cAD}$ & 0.455 & 0.015 \\
$\mathrm{H}$ & & &
\end{tabular}

EM, elastic modulus; $\mathrm{H}$, hardness; cAD, composite apparent density.

